\title{
How do we value academic time?
}

\author{
Mark A Schier
}

Swinburne University of Technology

\begin{abstract}
The extent of technology usage for managing teaching workloads is not completely known, but often extrapolated or inferred by academics' use of other technologies. This paper explores technology adoption, and attitudes toward use of technology by Australian university academics. We expected that academics would be familiar with general teaching technology tools and have some appreciation of other tools that may assist with their work and allow them to manage their time. We also expected that they would use these to identify and manage assignment work to free up time for other academic activities. To establish their usage of technology, responses to a series of questions about types and familiarity with technology tools, were collected via an online anonymous survey. It also asked for their understanding of a hypothetical assessment scenario and subsequent use of any time gained through using technology. The results from 75 Australian academics indicated that academics were familiar with and used standard teaching technology. Academics expressed a commitment to utilise any time saved for research, scholarship or teaching and learning related activities.
\end{abstract}

Keywords: Teaching technology, LMS, student assignment, academic feedback

\section{Background and Literature Review}

The purpose of the paper is to summarise the current situation for Australian University academics regarding their use of technology in their teaching practice, assessment and administrative tasks. It reports on data from a short survey on those measures, along with the academic's years of teaching, workload management and benefit of time savings. Briefly, the research question is: Does the use of learning technology by academic staff provide opportunities for scholarship and student engagement?

University academics are seeking different and innovative ways of using technology to manage the pressures of increased research outputs, increased student numbers, more diverse student cohorts, increased responsibilities and workloads associated with managing larger classes, and different modes of teaching and learning.

The Australian academic workload has been a source of concern for many years, particularly since the massification of higher education in the last two decades (Bradley 2008). Significant growth in the higher education sector, particularly in student populations, has resulted from policies introduced in the 1980s which radically altered student access to university. While student numbers have grown, teaching staff numbers have not increased at the same rate (Coates et al., 2009). Various Australian and international reports highlight increased staff to student ratios, and increased teaching loads as major factors driving the high level of stress leading to decreased job satisfaction (A. H. Winefield et al., 2002; T. Winefield et al., 2008; Strachan et al., 2012).

In Australia, a typical academic workload is defined as $40 \%$ research, $40 \%$ teaching and $20 \%$ service to the university and profession (Dobele et al., 2010). This is often colloquially known as the 40/40/20 rule. Within many Australian universities there are formal mechanisms to allocate individual academic workload based on the university's policy or enterprise agreement. In contrast, the informal arrangements are becoming less common as managerialism provides a different model for the modern university (O'Connor \& White, 2011). Hence, the individual workload for many academics' approaches, but does not equate to the 40/40/20 allocation.

Despite these workload models, university academics still face challenges in balancing their multiple roles of research and scholarship, teaching and learning, and leadership and engagement. Many academics search for ways to make their role less complex and more effective. One view is that: "those who seek to teach more flexibly and use technology to enhance their teaching find themselves faced with major changes in the ways they work, and frequently find conflicts with established practices governing workload allocation and professional recognition and reward" (Coaldrake \& Stedman, 1999). While there is a danger that assessment- 
centred learning systems adds further demand on the university academic's workload, some strategies designed for "minimal direct impact on teacher workload are most needed" (Anderson, 2008).

Learning environments are changing and reliance upon computer and software tools for all facets of education is increasing - for online, face-to-face and blended delivery modes.

Systems for the delivery of learning and educational materials are typically known as Learning Management Systems (LMS) or Course Management Systems (CMS). The uptake and use of tools such as these have been widespread (Vovides et al., 2007). In this paper we will refer to these collectively as LMS. Probably the most used systems at the time of the survey were Blackboard and Moodle. Canvas has entered the arena as a serious challenger in the meantime. These systems have effective features for delivery of learning materials (available for download by students), interactive material, quizzes, podcasts, online collaboration, asynchronous and synchronous discussions, and student submissions (uploaded by students). The upload of student assignments, essays, short-test responses, and discussion forums can be time and date stamped electronically to facilitate tracking submissions and verify receipt for the tutor and the student. This has benefits for the university academic with quality control aspects and completeness of records; and for the student, with security of submission and verification. While there is little doubt that LMS are well-utilised by students, more importantly, the tools for submitting assignments are also valued by students (Lonn et al., 2011).

There are three main aspects that emerge from the literature.

1. First, a mooted benefit of LMS for university academics is time saving, with which they can focus on teaching, because the administrative aspects of manually collating and allocating work are reduced by uploading and submitting documents and papers electronically. Both university academics and students value this feature (Lonn et al., 2011).

2. The second aspect is that of empowering students to be more in control of their learning. The advantages of electronic organising tools found within LMS and those which have been developed to work beside them or within them have meant a reduction in time for the more routine tasks, or as a specific example, the shifting of the responsibility of the student for selecting their own assignment topic using an automated tool (Schier \& Shields, 2009).

3. Finally, a major benefit is time saving for the university academic allowing more time for providing informative and quality feedback to students (Nicol \& Macfarlane-Dick, 2006), on both their achievement, and ways to improve their performance. This paper refers to feedback in general terms, and makes no attempt to address the types of feedback and methods, for example marked up manuscripts or electronic markups (Mills and Dalgarno 2007). For more general information about feedback the reader is referred to some reviews (Carless 2006), (Hounsell, 2003; Weaver, 2006). Care must be taken to include the time taken for use of the LMS, as some university academics spent more time using the LMS than the students for matters such as information and communication, although this reduced once they were more familiar with the system (Hamuy \& Galaz, 2010).

\section{Methodology}

The author used a cross-sectional design with a short online survey to investigate the use of technology in teaching and learning activities, including a broad range of tools such as LMS and other applications. The survey was given approval by the HREC at Swinburne University of Technology for wide distribution across all universities in Australia, and was essentially deemed low risk, with its anonymous data collection.

The online survey was brief and consisted of 11 quantitative questions (with 5-point Likert scales) followed by a single open-ended question. A technological teaching scenario was presented for consideration and response, including how any perceived time saving would be used. Additionally, years of teaching experience was collected as this may have an influence on either technology adoption, or an individual's time management systems. The survey began with an information screen with opt-in permission question and finished with an optout question (to facilitate removal of collected data if the respondent changed their mind about participation). The list of accredited Australian Universities was obtained from the (Australian-Education-Network) which listed forty Australian universities, two international universities and one specialist private university. Only the forty main institutions were utilised. The public website of each of the Australian universities was searched for the name of a senior person identified as responsible for teaching and learning or education. In many cases this was a director of teaching and learning, in others a Deputy Vice-Chancellor or Pro Vice-Chancellor for education. 
A personally addressed email was sent to each person identified asking them for assistance in inviting academics in their university to participate in the anonymous survey, with an attached invitation for their use with the online survey link. Direct invitations were also sent to known colleagues of the author and via other contacts within the sector. This work was carried out in the second half of 2015.

\section{Results and discussion}

In all almost cases, there was a response from that individual or delegate that they would pass the invitation on to academics. To protect anonymity of participants, there were no questions asking them to identify their institution, their department or discipline area. The survey results have been aggregated across all respondents.

\section{Demographics}

In all, 90 academics responded, with 75 completing the survey. The relevant group comprised $72 \%$ female and $27 \%$ male (1\% preferred not to answer). This differs from the reported distribution in universities (45\% female and $55 \%$ male), and may not be totally representative of the sector (Strachan et al., 2012). The years of teaching experience showed that the majority of respondents had taught for more than 6 years $(81 \%)$.

The proportion of women responding to the survey is consistent with findings that women are overrepresented in predominantly teaching roles, including casual positions that are exclusively teaching only (Marchant and Wallace 2013).

\section{Technology}

The overwhelming majority of respondents (80\%) had used Learning Management Systems in their work; with the experience being split largely between Blackboard and Moodle, and some with experience of both platforms. Table 1 indicates the types of LMS used by respondents, noting that these are not exclusive categories, as they may have multiple selections for this question. Overall, $84 \%$ had experience with Blackboard, and $48 \%$ experience with Moodle. Some other systems were also used, but the experience of these was limited in the surveyed group. Given that Canvas had around 30\% of North American market share in 2019 and $15 \%$ in 2015 (PhilonEdTech, 2020), it is reasonable to assume that the $16 \%$ per cent in other category would include that platform.

Table 1. Experience of LMS packages

\begin{tabular}{|l|l|}
\hline Platform & Used \\
\hline Blackboard & $84 \%$ \\
\hline Moodle & $48 \%$ \\
\hline Canvas/Other & $16 \%$ \\
\hline Desire2Learn & $5 \%$ \\
\hline Edmodo & $3 \%$ \\
\hline
\end{tabular}

Aside from LMS, the common technologies used for academic work (see Figure 1), included presentation software 97\%; word processing 95\%; spreadsheet 90\%; and scheduling (calendar etc) 58\%. The results are not surprising here given the anecdotal criticism of lectures being overwhelmed with PowerPoint slides of average quality, and often termed "Death by PowerPoint". The other technologies are not particular to academic roles and are generally used among professional workers. 


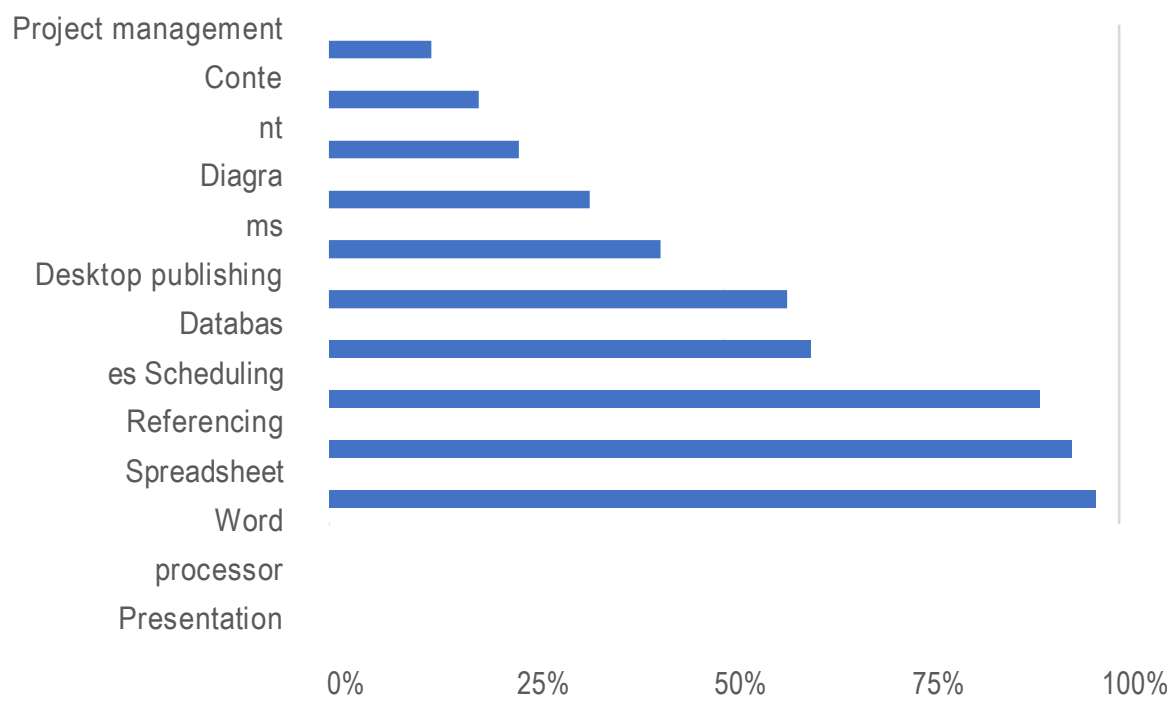

Figure 1. Technology reported by academics used for their work

\section{Purpose for using technology}

More interesting than these findings is the proportion of academics (slightly more than 60\%) using technological tools for assignment management or administration. Following this, most academics expressed a view that they would consider using an automated tool for assignment selection and management as it would either save time, simplify the task, provide equity for students, assist with better distribution between assessors or reduce processing errors (Table 2). Only 15 per cent indicated no perceived value in such technological tools.

Additionally, nearly 80 per cent of academics would use an automated tool for managing assignments if available. These results indicate that there is a widespread acceptance of technological tools in academia for teaching related purposes. There was also a theme in the open-ended comments relating to availability and accessibility of tools, for example one respondent stated that they would: “... probably only make use of a tool that fits well within the existing toolset, mainly Blackboard". This was echoed by similar sentiments from others as they were concerned, almost frustrated about the sustainability and longevity of some tools; "For instance, academics have just been able to set up an automated system and get it running smoothly when the institute decides to change the LMS, and everything has to be done all over again”.

Table 2. Use of tools if they saved significant time

\begin{tabular}{|l|l|}
\hline Likelihood & \\
\hline highly likely & $52 \%$ \\
\hline likely & $27 \%$ \\
\hline neither likely nor unlikely & $8 \%$ \\
\hline unlikely & $3 \%$ \\
\hline highly unlikely & $4 \%$ \\
\hline N/A & $5 \%$ \\
\hline
\end{tabular}

When asked how any time saving would be utilised, the top three answers were research/scholarship (42\%), teaching enhancement (32\%) and improved feedback to students (19\%) (as illustrated in Figure 2). This is informative about the way that academics approach the task of their substantive work, with its mixture of roles $(40 / 40 / 20)$. It is also interesting to note the trend towards using any saved time for learning and teaching related activities of around 51\%, compared to $41 \%$ for research and scholarship (Marchant and Wallace 2013). This may be a limitation of the survey sample, where it was more likely to be opened and completed by those with an interest in learning and teaching.

Part of the survey was the scenario that was placed before the respondents with a view to understanding their 
interpretation and response.

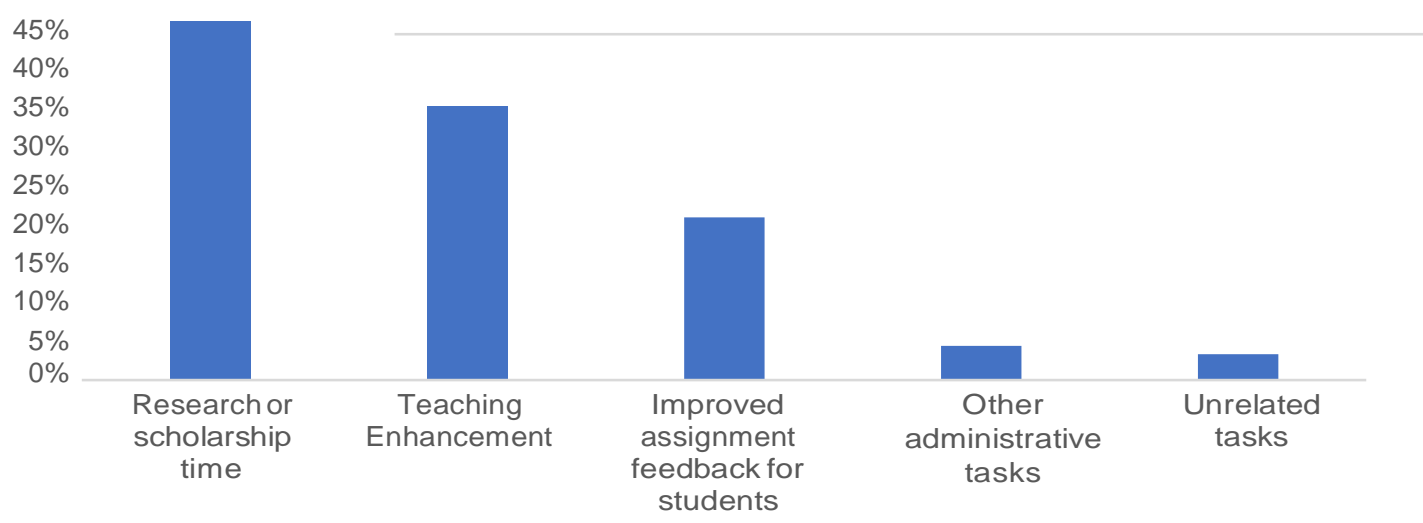

Figure 2. Use of time saved as a proportion of academics surveyed

You teach a cohort of 80 students in a unit, and one assessment is a 3000-word essay. There are 8 topics for the students to choose from, and there are 4 tutors who will grade the essays ( 2 topics each). In an ideal world, the demand for the essay topics will be matched and each tutor will grade 10 essays for each topic. Of course, in the real world, 52 students choose topic 5 and the other 28 students are evenly spread between the others (about 4 per topic). You are concerned about the uneven distribution of students choosing topics unless you impose a quota or limit per topic. How would you manage this (or how have you managed this in the past)?

1. Manual management via email or written request

2. Email and spreadsheet (students email their topic request)

3. LMS tool (for example self-enrolled groups within package)

4. Other automated tool (for example Swinburne University of Technology assignment allocation tool)

5. Would not set any quotas, tutors would grade whatever they receive.

To simplify the categories 2, 3 and 4 were grouped together as automated or semi-automated response. The responses for this question were setting no quotas (47\%), automated or semi-automated response (38\%) and manual management (15\%). These are show in Table 3.

Table 3. Assignment selection

\begin{tabular}{|l|l|l|}
\hline Category & Choice & Aggregate \\
\hline No quotas set & $47 \%$ & $47 \%$ \\
\hline Email and spreadsheet & $8 \%$ & ü \\
\hline LMS tool & $29 \%$ & $\begin{array}{l}\text { b } 38 \% \\
\text { Another tool }\end{array}$ \\
\hline Manual management & $1 \%$ & $15 \%$ \\
\hline
\end{tabular}

These results were surprising, as one might expect that academics would take advantage of tools to assist in managing assessment and assignment allocation. One possible reason for the response is that academics had not any experience of the scenario before, and one respondent provided feedback to this effect: "Your questions don't quite match my teaching". Another respondent used a different approach to assignment setting: "To improve consistency between markers I generally set up only one essay question that all students must respond to". Further a third person suggested looking deeper as it may be a: “... design problem with the topics offered and also alignment between the assessments, the desired outcome and the content". This indicates that some scenarios may be applicable to different academic disciplines and an ability to think beyond this is difficult for a small proportion (only 3 comments were made about this aspect out of the 75 respondents). 
The overall outcome is that academics are well versed and experienced in traditional teaching technology of PowerPoint presentation, word processing, spreadsheet and ancillary software. Many are actively using LMS and associated tools to assist in managing their workload. Academics are comfortable with taking advantage of potential time-savings for their research, teaching or scholarly activities. However, they are less comfortable with investing time into unproven and unsuitable tools. LMS are continually evolving and developing greater capability, and some tools developed for a specific application (Schier \& Shields, 2009) are now options available in current LMS.

\section{Limitations}

The cohort of participants was skewed toward female academics, and not representative of the academic population (Strachan et al., 2012). It is reflective, however of a gender-based reality where women are overrepresented in university teaching roles (Marchant \& Wallace, 2013). Alternatively, it could reflect an attitude to teaching by men, or the reality of increased workload pressures on those with fulltime academic employment. This cannot be determined from the data collected, as participants were not asked to report their employment status.

No data were identifiable by institution, so it is not possible to draw any inferences around location or culture of different institutions. This could be explored in the future, and would provide interesting data around the appreciation of educational technology and its use within the sector.

It is difficult to quantify the time savings in academia. Work is not easily compartmentalised and there is significant overlap between teaching and research interests, at the teaching-research nexus (Geschwind \& Broström, 2015). The overwhelming pressures on academics drives their perceptions of free-time, and this would be largely directed to research and scholarship. This is consistent with time-poor academics with pressure to publish their work.

\section{Conclusion}

In all, the study shows that there is considerable adoption and use of technology by Australian academics for their teaching and related activities. Where they have managed to save time, they reported that they would use this for research, teaching, student feedback, and other scholarly pursuits.

\section{References}

Anderson, T. (2008). Toward a theory of online learning. In T. Anderson (Ed.), Theory and practice of online learning. 2 (pp. 109-119). Edmonton: AU Press, Athabasca University.

Australian-Education-Network List of Australian Universities. http://www.australianuniversities.com.au/list/. Accessed February 2018.

Bradley, D. (2008). Review of Australian higher education: Discussion paper: Department of Education, Employment and Workplace Relations.

Carless, D. (2006). Differing perceptions in the feedback process. Studies in Higher Education, 31(2), 219-233, doi:10.1080/03075070600572132.

Coaldrake, P., \& Stedman, L. (1999). Academic work in the twenty-first century. Canberra, Higher Education Division, Training and Youth Affairs.

Coates, H., Dobson, I. R., Goedegebuure, L., \& Meek, L. (2009). Australia's casual approach to its academic teaching workforce. People and Place, 17(4), 47-55.

Dobele, A., Rundle-Thiele, S., Kopanidis, F., \& Steel, M. (2010). All things being equal: Observing Australian individual academic workloads. Journal of Higher Education Policy and Management, 32(3), 225-237.

Geschwind, L., \& Broström, A. (2015). Managing the teaching-research nexus: ideals and practice in researchoriented universities. Higher Education Research \& Development, 34(1), 60-73, doi:10.1080/07294360.2014.934332.

Hamuy, E., \& Galaz, M. (2010). Information versus communication in course management system participation. Computers \& Education, 54(1), 169-177.

Hounsell, D. (2003). Student feedback, learning and development. Higher education and the lifecourse, 67-78.

Lonn, S., Teasley, S. D., \& Krumm, A. E. (2011). Who needs to do what where?: Using learning management systems on residential vs. commuter campuses. Computers \& Education, 56(3), 642-649.

Marchant, T., \& Wallace, M. (2013). Sixteen years of change for Australian female academics. Australian Universities' Review, 55(2). 
Mills, C., \& Dalgarno, B. A conceptual model for game-based intelligent tutoring systems. In ASCILITEAustralian Society for Computers in Learning in Tertiary Education Annual Conference, Singapore, 2007: Australasian Society for Computers in Learning in Tertiary Education

Nicol, D. J., \& Macfarlane-Dick, D. (2006). Formative assessment and self-regulated learning: A model and seven principles of good feedback practice. Studies in Higher Education, 31(2), 199-218.

O'Connor, P., \& White, K. (2011). Similarities and Differences in Collegiality/Managerialism in Irish and Australian Universities. Gender and Education, 23(7), 903-919.

PhilonEdTech https://philonedtech.com/state-of-higher-ed-lms-market-for-us-and-canada-2019-mid-yearedition/ [accessed October 2020]

Schier, M. A., \& Shields, D. An online tool for managing student assignment selection. In ascilite: Same places, different spaces., Auckland, 2009

Strachan, G., Troup, C., Peetz, D., Whitehouse, G., Broadbent, K., \& Bailey, J. (2012). Work and Careers in Australian Universities: Report on Employee Survey. Centre for Work, Organisation and Wellbeing, Griffith University.

Vovides, Y., Sanchez-Alonso, S., Mitropoulou, V., \& Nickmans, G. (2007). The use of e-learning course management systems to support learning strategies and to improve self-regulated learning. Educational Research Review, 2(1), 64-74.

Weaver, M. R. (2006). Do students value feedback? Student perceptions of tutor's written responses. Assessment \& Evaluation in Higher Education, 31(3), 379-394, doi:10.1080/02602930500353061.

Winefield, A. H., Gillespie, N., Stough, C., Dua, J., \& Hapuararchchi, J. (2002). Occupational stress in Australian universities: A national survey. https:/www.vawo.nl/wpcontent/uploads/2012/06/OccupationalstressAustraliauniversities.pdf.

Winefield, T., Boyd, C., Saebel, J., \& Pignata, S. (2008). Update on national university stress study. The Australian Universities' Review, 50(1), 20-29.

Schier, M. A. (2020). How do we value academic time? In S. Gregory, S. Warburton, \& M. Parkes (Eds.), ASCILITE's First Virtual Conference. Proceedings ASCILITE 2020 in Armidale (pp. 12-18).

https://doi.org/10.14742/ascilite2020.0120

Note: All published papers are refereed, having undergone a double-blind peer-review process.

The author(s) assign a Creative Commons by attribution licence enabling others to distribute, remix, tweak, and build upon their work, even commercially, as long as credit is given to the author(s) for the original creation.

(C) Schier, M. A. (2020) 